\title{
Moda e sustentabilidade: o que pensam futuros profissionais da área de Design
}

Gabriel Coutinho Calvi

Mestrando em gestão do conhecimento nas organizações pela Unicesumar./ gabrielcalvi@hotmail.com Orcid: 0000-0003-3336-5033/ lattes

\section{Ana Paula Furlan}

Mestre em educação para o ensino da matemática pela UEM. / paulamoda@hotmail.com

Orcid: 0000-0001-9344-9621/ lattess

Paula Piva Linke

Doutora em Ciência Ambiental pela USP. / paulapivalinke@gmail.com

Orcid: 0000-0002-3634-7765/ lattes 


\title{
Moda e sustentabilidade: o que pensam futuros profissionais da área de Design
}

\begin{abstract}
RESUMO
Esta pesquisa, de caráter qualitativo, objetiva investigar a compreensão que os acadêmicos de um curso de Design de Moda possuem em relação à sustentabilidade, especialmente na área da moda. Os dados foram coletados durante uma intervenção pedagógica, no contexto da disciplina de Desenvolvimento de Produto. Participaram da pesquisa 20 acadêmicos do $3^{\circ}$ ano do curso de Design de Moda. Estes foram mobilizados à responder um questionário, apresentar seminários e produzir textos acerca da temática sustentabilidade. A análise dos dados coletados por meio do questionário, de filmagens, apresentação dos seminários e dos escritos, evidenciou que os acadêmicos além de ampliarem a compreensão acerca do tema sustentabilidade, refletiram sobre a importância de este ser levado em conta no campo da moda, futura área de atuação dos sujeitos pesquisados.
\end{abstract}

Palavras-chave: Designer de Moda; Educação Ambiental; Sustentabilidade. 


\title{
Fashion and sustainability: what future professional designers think
}

\begin{abstract}
This qualitative research aimed to ascertain the sustainability knowledge academic students of a Fashion design course possessed. The first researcher collected data during a pedagogical intervention, within the context of the product development discipline. Twenty third-year students from the above-mentioned course participated in the research and mobilized to respond to a questionnaire, present seminars and produce texts about sustainability. The data analysis, collected through a questionnaire, the seminars videos and written texts, showed that the students, in addition to increasing their understanding about sustainability, reflected on its importance in the field of fashion, future work area of the researched students.
\end{abstract}

Keywords: Fashion Designer; Environmental Education;

Sustainability. 


\title{
Moda y sostenibilidad: que piensan los futuros profesionales del diseño
}

\begin{abstract}
RESUMEN
Esta investigación cualitativa tiene como objetivo investigar la comprensión que los académicos de un curso de Diseño de Moda tienen en relación a la sostenibilidad, especialmente en el área de la moda. Los datos fueron colectados durante una intervención pedagógica en el contexto de la disciplina de Desarrollo de Producto. Veinte estudiantes del tercer año del curso de Diseño de Moda participaron en la investigación, quienes fueron movilizados para responder un cuestionario, presentar seminários y producir textos sobre el tema de la sostenibilidad. El análisis de los datos recopilados a través del cuestionário, filmación, presentación de los seminários y los escritos, evidenciaron que los académicos, además de ampliar la comprensión sobre el tema de la sostenibilidad, reflexionaron sobre la importancia de que se tenga en cuenta en el campo de la moda, futura área de especialización de los sujetos de investigación.
\end{abstract}

Palabras clave: Diseño de moda; Educación ambiental; Sostenibilidad. 


\section{INTRODUÇÃO}

A temática sustentabilidade tem sido foco de interesse de diferentes áreas e envolve um número considerável de pesquisadores. Dentre os vários trabalhos, destacam-se Jacobi (2005), Amador (2007), Manzini e Vezzoli (2008). A importância do tema se deve a uma série de alterações climáticas, ocasionadas pela interferência do homem no meio em que vive. Assim, pensar em sustentabilidade pressupõe ações em vários campos e dimensões, tais como o campo social e econômico, a conservação e o gerenciamento de recursos naturais, entre outros.

Em uma perspectiva socioambiental, a questão da sustentabilidade se caracteriza como proposta educativa inovadora, com a finalidade de proporcionar, aos cidadãos, uma formação de conhecimentos que favoreça a sua participação na sociedade. Manzini e Vezzoli (2008, p. 57) relatam:

O próprio tema da sustentabilidade é o primeiro dos novos valores universais em potencial. E nos propõe, de fato, o valor da responsabilidade nos confrontos das gerações futuras, e, consequentemente, o objetivo de não prejudicar os equilíbrios ambientais que nossa vida e a esperança futura de vida na terra se baseiam..

O conceito de sustentabilidade ambiental cresceu significativamente em diversas áreas, e com a gestão da moda não foi diferente. Hoje se incorporam, em todos os âmbitos dessa área, ações estratégicas aos processos que envolvem o produto desde sua criação e design, comunicação, distribuição e descarte. A expectativa da construção de novos conceitos tem como foco incentivar a mudança de hábito tanto daqueles que desenvolvem e produzem, como daqueles que consomem, conscientizandoos das necessidades relativas à proteção e manutenção do meio ambiente. 
Os documentos legislativos oficiais responsáveis pelo meio ambiente, ressaltam que as instituições de ensino superior devem se preocupar com aspectos ambientais, ao pensarem seus projetos pedagógicos. Nesse sentido, as Diretrizes Curriculares Nacionais para a Educação Ambiental (DCNEA) estabelecem, como parte integrante dos projetos institucionais e pedagógicos da educação básica e superior, "[...] o compromisso da instituição educacional, o papel socioeducativo, ambiental, artístico, cultural e as questões de gênero, etnia, raça e diversidade que compõem as ações educativas, a organização e a gestão curricular" (BRASIL, 2012, p. 5). Assim, entende-se que o designer de moda precisa de subsídios, em sua formação, que sustentem sua trajetória profissional pautada na prática da educação ambiental, assim como da sustentabilidade, para que possa apoiar e viabilizar o desenvolvimento de produtos sustentáveis.

Deveria ser preocupação das instituições de ensino superior proporcionar espaços para que os alunos sejam capazes de valorizar a superação pessoal e o esforço para alcançar novas metas coletivas e pessoais, pois não são somente conteúdos que fazem um bom profissional, mas também a capacidade de transformar os conhecimentos para o bem da cidadania, de forma ética e moral (MARTÍN, 2006). Portanto, diante desse contexto, procuramos responder nesta pesquisa à seguinte questão: é possível construir conhecimentos acerca da sustentabilidade com acadêmicos do Curso de Moda por meio de uma intervenção pedagógica que contemple o estudo dessa temática?

Portanto, apresenta-se uma breve explanação sobre meio ambiente e sustentabilidade e, seguindo, dar-se-á ênfase ao conceito do termo moda e sua relação com a sustentabilidade. $\mathrm{Na}$ sequência, apresenta-se os procedimentos metodológicos da pesquisa e a discussão de 
seus resultados. Por fim, expõe-se algumas considerações acerca das questões investigadas, refletindo sobre a contribuição deste estudo na formação de profissionais da moda.

\section{MEIO AMBIENTE, SUSTENTABILIDADE E MODA}

O avanço desenfreado das diferentes atividades humanas que impactam o ambiente caracteriza-se como uma ameaça constante à biodiversidade. Destaca-se, dentre tais atividades, o desmatamento, uso excessivo de agrotóxicos, uso abusivo dos recursos naturais, excesso de dejetos lançados ao solo, dentre outras. Tais atividades humanas, por sua vez, podem estar relacionadas à falta de informação, compreensão e percepção da sociedade no que diz respeito ao meio ambiente e à problemática ambiental. O homem, ao agir sobre a natureza, ao mesmo tempo em que a transforma, torna-se o destruidor dela. Nessa percepção, Reigota (1995, p. 14) indica que os veículos de comunicação divulgam as próprias concepções, muitas vezes, colocandoas como verdades absolutas e complementa relatando que "[...] não existe um consenso sobre meio ambiente na comunidade científica em geral. Supõe-se que o mesmo deve ocorrer fora dela". Com essa diversidade de possibilidades para o significado atribuído ao termo ambiente, pode acontecer uma distorção do mesmo. Evidencia-se, também, a visão de Dias (2004), quando argumenta que o ambiente é visto como o complexo que envolve coisas vivas e não vivas da Terra, interferindo no ecossistema e na vida em todas as suas formas. Portanto, o ambiente não é formado apenas por flora e fauna, água, solo e ar, como tradicionalmente definido. Faz-se necessário considerar os aspectos políticos, éticos, econômicos, sociais, ecológicos e culturais para uma visão global do ambiente (DIAS, 2004). 
É por meio da educação que os indivíduos se tornam aptos para sensibilizar a comunidade e promover mudanças de atitudes e valores, capazes de garantir a conservação meio em que vive e, consequentemente, assegurar a continuidade da vida. Leff (2012) complementa essa questão, argumentando sobre a impossibilidade de solucionar os crescentes e complexos problemas ambientais sem que ocorra uma mudança radical nos sistemas de conhecimento, valores e de comportamentos.

Quanto à sustentabilidade, é relevante destacar que este termo surgiu, pela primeira vez, no contexto do livro escrito por Donella Meadows e Jorgen Randers, em 1972, intitulado de "Os Limites do Crescimento", no qual apresenta conceitos associados à sustentabilidade pautados no uso equilibrado dos recursos naturais para satisfação do próprio bem-estar, levando em conta as gerações futuras que terão o direito ao uso dos mesmos recursos, sendo importante que estes recursos estejam ainda disponíveis.

Neste contexto da sustentabilidade, pode-se dizer que este conceito tem sido bastante utilizado, na atualidade, como forma de dar suporte aos processos econômicos dado que algumas organizações o estão empregando na designação de suas ações.

Compreender, de fato, a questão da sustentabilidade conduz a uma reflexão acerca de ações sobre o meio ambiente. Nesse sentido, Amador (2007) salienta que a sustentabilidade é um conceito sistêmico, relacionado com a continuidade dos aspectos econômicos, sociais, culturais e ambientais da sociedade. Logo, propõe-se a ser um meio de configurar a civilização e atividades humanas de tal forma que a sociedade, os seus membros e as suas economias, possam satisfazer suas necessidades e expressar o seu maior potencial no presente ao mesmo tempo que preservam a biodiversidade e os ecossistemas naturais, 
planejando e agindo, de forma a atingir pró-eficiência na manutenção desses ideais.

A sustentabilidade abrange vários níveis de organização, desde a vizinhança local até o planeta como um todo. Para um empreendimento humano ser sustentável, necessita compreender quatro requisitos básicos: o empreendimento precisa ser ecologicamente correto; economicamente viável; socialmente justo; e culturalmente aceito (JACOBI, 2005). Complementando essas premissas, Amador (2007) e Benvenuti (2008) destacam que o pensar na sustentabilidade da sociedade requer um novo modo de agir:

[...] ambientalmente sustentável no acesso e uso dos recursos naturais e na preservação da biodiversidade; que seja socialmente sustentável na redução da pobreza e das desigualdades e na promoção da justiça social; que seja culturalmente sustentável na conservação dos sistemas de valores, práticas e símbolos de identidade de que determinam integração nacional ao longo do tempo; e que seja politicamente sustentável aprofundando a democracia e garantindo o acesso à participação de todos os setores de sociedade nas decisões públicas. Esse estilo tem como diretriz uma nova ética de desenvolvimento, uma ética na qual os objetivos econômicos de progresso material subordinam-se às leis que governam o funcionamento dos sistemas naturais, bem como à critérios superiores de respeito à dignidade humana e de melhoria na qualidade de vida das pessoas (BENVENUTI, 2008, p. 228, grifos nossos).

De acordo com os autores citados, faz-se necessário respeitar os limites da natureza, pensando na qualidade de vida das pessoas, em termos de participação política, o que exige uma nova ética no comportamento, frente ao meio ambiente e à sociedade.

Apresentados os conceitos e características sobre sustentabilidade, faz-se necessário contextualizar sobre a temática da moda, para compreender sua relação com a sustentabilidade. Assim, Joffily (1999), Simmel (1961) e Roche (2007) indicam que a terminologia da moda se 
caracteriza como um vasto fenômeno social, o qual aplica-se a todas as áreas sociais constituindo uma relação de identidade. Portanto, pode-se entender que a vida social não é apenas compartilhada, mas, de certa forma, padronizada.

Barthes (2005) vê a moda como um fenômeno de comunicação, afirmando que o homem se vestiu para além dos motivos de proteção ou pudor. Assim, o homem "[...] vestiu-se para exercer sua atividade significante [...] logo é um ato profundamente social" (BARTHES, 2005, p. 364). Não apenas um ato social, mas o autor afirma haver um sistema da moda que rege os processos de mudança no vestuário e que essas mudanças podem ser identificadas em períodos de longa duração e, em muitos casos, se repetem ao longo do tempo (BARTHES, 1967).

Para Paolo Sorcinelli, a moda pode ser compreendida como "[...] um costume presente em certas sociedades, para as quais as roupas, os acessórios, os objetos, as tendências culturais renovam-se ciclicamente por meio de formas comuns" (SORCINELLI, 2008, p. 158).

Cabe ainda destacar a renovação das tendências culturais. A moda não abarca somente a esfera do vestuário, embora essa seja sua maior representante, mas engloba outras esferas como mobiliário, arquitetura, estética e arte, que são influenciados pelas chamadas tendências. Assim sendo, pode-se entender a moda como:

[...] fenômeno social da mudança cíclica dos costumes e dos hábitos, das escolhas e dos gostos, coletivamente validado e tornado quase obrigatório. Em relação à moda, o termo costume, na acepção de hábito constante e permanente que determina o comportamento, a conduta, o modo de ser de uma comunidade, de um grupo social, remete ao conceito de sistema, de estrutura, ou seja, um conjunto de vários elementos relacionados entre si (CALANCA, 2008, p 11-12). 
Embora a moda traga consigo toda a percepção e construção de um universo simbólico, cabe ressaltar que ela engloba outras esferas, os quais Lipovetsky (2010) explora ao problematizar a efemeridade, o consumo e a produção da moda, do objeto chamado roupa. Logo, quando pensamos em vestuário, o termo moda se sobressai, assim como a frivolidade. No entanto, por trás da moda, existe o objeto roupa, e esse objeto torna-se um produto que carrega consigo uma carga simbólica, as tendências e o próprio conceito de estar ou não na moda. Por trás dessa roupa existe um universo extremamente complexo que a produz e a transforma em objeto de desejo e para o qual a indústria terá um papel determinante.

O século $X X$ marcou a história na produção de roupas e também da moda, pois efetivou a indústria têxtil por meio do sistema de produção em massa, a confecção. Mas, mais do que a roupa, formou-se aí uma duplicidade na concepção da moda. "De um lado temos o crescente desenvolvimento da indústria e a criação de tendências que geram mudanças significativas no design da roupa (seu feitio, material e durabilidade)" (BERLIM, 2012, p. 20). Por outro, temos a moda como responsável por essa indústria, que apresenta duas importantes facetas: "[...] a do produto (roupas e acessórios) e a do conceito gerador de tendências, que expressa nossas necessidades emocionais e psicológicas" (BERLIM, 2012, p. 20).

Essas necessidades são momentaneamente sanadas pelo consumo desses produtos, que são descartados após saírem de moda e outra necessidade surge, ou seja, a vida útil desses produtos não está relacionada à durabilidade ou utilidade, mas sim à satisfação do desejo imediato, à estética, ao julgamento alheio, se está ou não na moda. A moda sobrevive do consumo, se alimenta dele e o 
potencializa por meio do lançamento de novas tendências (BERLIM, 2012).

Portanto, a moda transformou-se, sobretudo, em um elemento de consumo excessivo, originando-se dele a necessidade de mais produtos e, consequentemente, maior uso de matéria prima, maior demanda energética e uso inadequado dos recursos naturais, gerando, a partir do modelo de produção dominante, diversos impactos ambientais (BERLIM, 2012).

O consumo exagerado sempre esteve nas discussões no que diz respeito aos produtos de moda, entretanto, tende a reconfigurar-se, pois, o grande problema da acessibilidade que a moda traz, é que o consumidor envolvido pelo objeto de desejo - a roupa - não se atenta para o fato de que, desde a criação desse produto até sua chegada ao destino final, passa por longos processos de fabricação, tornando-se mina de esgotamento dos recursos naturais.

O segmento de moda envolve uma série de processos e atividades que buscam transformar as necessidades e desejos de consumo em realidade. Este ato começa na escolha da fibra a ser utilizada - natural (animal, vegetal ou mineral) ou química (artificial ou sintética) - a cadeia produtiva que envolve a seleção dos fios, o tipo de tecelagem que será utilizada (malharia, tecidos planos, tecidos não tecidos e outros), os processos de tingimento e beneficiamento, os processos de transformação, a logística de distribuição, as embalagens, os pontos de vendas, o consumo e o descarte final, e cada uma dessas etapas acaba gerando resíduos sólidos dos mais diversos tipos e nas mais variadas quantidades (PEZZOLO, 2012).

Portanto, torna-se difícil conciliar a moda com o desenvolvimento ambientalmente sustentável, pois, pelo individualismo, as pessoas não se dispõem a considerar o interesse geral, a renunciar aos privilégios adquiridos 
(LIPOVETSKY, 2010). As ações para um mundo sustentável dependem da coletividade e também do trabalho individual. Logo, a conscientização é o desafio tanto para a moda, quanto para outros segmentos da sociedade. Nesse sentido, a criatividade para conciliar princípios de sustentabilidade, os fatores econômicos viáveis e menores impactos ao ambiente são de grande valia no projeto do produto de moda.

Para se pensar em ações de sustentabilidade na moda, o maior desafio que se impõe a gestão empresarial é a dificuldade de conciliar produtividade, competitividade e sustentabilidade. A questão da sustentabilidade ambiental, na produção e no consumo de bens, é uma preocupação, e já foram desenvolvidas estratégias nas últimas décadas para tentar minimizar os problemas ambientais tais como; produção mais limpa, tecnologias limpas, ecodesign, design para a sustentabilidade, entre outras. Portanto,

[...] A preocupação ambiental, ainda na fase de projeto, é muito oportuna por ser uma solução preventiva, e não uma solução paliativa para os danos já causados pela empresa na produção de determinados bens. Ao projetar um produto, o designer ou projetista precisa ter em mente o conceito de ciclo de vida e procurar, desta maneira, minimizar os impactos negativos que o mesmo possa vir a causar ao meio ambiente em todas as fases do seu ciclo (MELLO et al., 2007, p. 56).

O que Mello et al. (2007) apresentam está ligado a importância de se pensar em alternativas na fase do projeto do produto, relacionadas ao seu ciclo de vida, com a intenção de minimizar os impactos ocasionados durante sua produção. Assim, salienta-se que 0 conceito de sustentabilidade não se resume em deixar de usar "alguma coisa" porque causará prejuízo ao meio ambiente, mas, está ligado à procedência do objeto que será consumido, e se foi produzido visando a preservação do meio ambiente. 


\section{METODOLOGIA}

Esta pesquisa norteia-se pela abordagem metodológica qualitativa, de acordo os pressupostos de Bogdan e Biklen (1994). Nessa abordagem, o pesquisador entende que as ações são mais compreendidas, quando observadas no seu ambiente natural, portanto, o interesse do pesquisador se dá mais pelo processo que pelos resultados, e a sua preocupação centra-se no contexto e no contato direto com o objeto de estudo. Dessa forma, o pesquisador, como o instrumento principal da investigação, tem como objetivo a compreensão do comportamento e da experiência humana. Frente a essas considerações, a pesquisa qualitativa se tornou apropriada para investigar a contribuição de uma intervenção pedagógica na produção de significados sobre sustentabilidade nos acadêmicos do Curso de Moda.

Os dados foram coletados no contexto de uma atividade pedagógica no $1^{0}$ semestre de 2014, envolvendo 20 acadêmicos do Curso de Bacharelado em Moda, da disciplina de Desenvolvimento de Produto que responderam um questionário diagnóstico, composto por cinco questões: 1) 0 que você entende por meio ambiente?; 2) Você já ouviu falar em sustentabilidade? Se sim, cite por qual meio de comunicação. ( ) Livros ( ) TV ( ) Jornais ( ) Revistas ( ) Internet ( ) Outros. Quais?; 3) Qual a sua compreensão a respeito da sustentabilidade?; 4) Que recursos você conhece, na moda, que contribuem para a sustentabilidade?; 5) O que você sugere, como futuro designer de moda, para colocar em prática conceitos de sustentabilidade?

$\mathrm{Na}$ sequência, foi ministrada uma aula expositiva dialógica acerca da Educação Ambiental e Sustentabilidade. Iniciou-se a aula com um histórico da educação ambiental, desde as primeiras percepções das agressões ao ambiente e 
a forma como foram percebidos os primeiros impactos. $\mathrm{Na}$ sequência, foram apresentados os principais acontecimentos e eventos que deram suporte às percepções, e discutido sobre a compreensão de sustentabilidade na atualidade. Destaca-se os principais pontos abordados: a) Entendendo Educação Ambiental e Sustentabilidade; b) Eventos Científicos sobre as Preocupações com o Ambiente; c) Desenvolvimento Sustentável versus Sustentabilidade.

Após discussão dos conteúdos mencionados, foram fornecidos vários artigos sobre sustentabilidade e sustentabilidade na moda, os quais foram lidos e discutidos pelos acadêmicos e utilizados como base para a elaboração e apresentação de seminários. Estes seminários foram elaborados por grupos de três ou quatro integrantes, com apresentação para o grande grupo (toda a turma). O Quadro 1 apresenta um breve resumo dos artigos selecionados e fornecidos aos acadêmicos para a elaboração dos seminários.

Como última etapa da atividade pedagógica desenvolvida, foi solicitada, aos alunos, a produção individual de um texto explicitando as novas percepções acerca da educação ambiental e da sustentabilidade. Ressalta-se a ênfase está voltada aos resultados relacionados à questão da sustentabilidade, os quais foram analisados de acordo com os pressupostos da pesquisa qualitativa e interpretados à luz do referencial teórico estudado.

Quadro 1: textos que fundamentaram os seminários.

1) Sustentabilidade: um objetivo comum, diferentes perspectivas (João Victor Inácio Pereira). O artigo traz um contexto histórico e uma base conceitual do desenvolvimento sustentável $e$, posteriormente, discute a responsabilidade dos países desenvolvidos e em 
desenvolvimento nesse processo de mudança em prol da sustentabilidade. Enquanto os países em desenvolvimento possuem problemas, como o grande crescimento populacional e a falta de tecnologia para a exploração eficiente dos recursos naturais, os países desenvolvidos consomem excessivamente esses recursos, por seu estilo de vida.

2) Moda: da Estética à Ética Ambiental Biocêntrica (Neide Köhler Schulte). O artigo aborda a natureza, enfatizando-a como um tema frequente que inspira as coleções de moda. Recentemente, a moda passou a considerar a natureza não apenas como um tema para inspiração, mas, sim, como algo que deve ser considerado e respeitado. Falar em respeito e consideração é falar de ética. $\mathrm{Na}$ Conferência Rio 92, introduziu-se o conceito de desenvolvimento sustentável, definido como 'um crescimento para todos, assegurando, ao mesmo tempo, a preservação dos recursos para as futuras gerações. Em uma perspectiva ambiental biocêntrica, a preocupação é diretamente com a natureza, a qual deve ser preservada e recuperada, independentemente da sua função utilitária para a preservação da espécie humana.

3) 0 novo consumidor de moda e a Sustentabilidade (Ereany Refosco; Karla Mazotti; Márcia Sotoriva; Ana Cristina Broega). O artigo traz um alerta acerca da preocupação mundial em torno das questões ambientais, advertindo que se torna premente a análise de um novo comportamento do consumidor. O artigo diz respeito, também, ao modo como inserir a moda, considerada uma atividade efêmera e movida pelo consumo, no perfil de um novo consumidor consciente, em um contexto de desenvolvimento sustentável.

4) Sustentabilidade Ambiental: um desafio para a moda (Neide Köhler Schulte e Luciana Lopes). O artigo 
propõe uma reflexão sobre um paradigma que se estabeleceu no século XXI, 'o desenvolvimento ambientalmente sustentável', e sua implicação na criação de produtos para o vestuário. O consumidor, a indústria, o criador de novos produtos, todos têm papéis determinantes na consolidação desse paradigma. Os impactos ambientais devem ser considerados em todas as etapas nos projetos de novos produtos, da origem da matéria prima até o descarte pelo consumidor. O desenvolvimento sustentável é um grande desafio para a criação de novos produtos para o vestuário de moda, pois o ciclo de vida muito curto desses produtos e o apelo ao consumismo representam um entrave. Diante desse contexto, são identificados novos cenários para a moda.

5) A Importância do Consumo Consciente no Mercado de Moda (Cristina Nunes de Aguiar; Emanuelle Martins; Rodrigo Nuns Matos). O artigo apresenta um estudo bibliográfico e de observação sobre como o ciclo da moda incentiva o consumo por impulso e o porquê dessa influência junto aos consumidores; traz, também, uma nova visão sobre a direção para a qual esse consumo caminha, ligado à nova cultura da sustentabilidade - o consumo consciente e, assim, atinge seu objetivo de elencar possíveis caminhos que contribuam, de maneira prática, para essa nova cultura.

6) Sustentabilidade ambiental das organizações através da produção mais limpa ou pela Avaliação do Ciclo de Vida (Roberta Tomasi Pires Hinz; Luiz V. Dalla Valentina; Ana Claudia Franco). O artigo aborda a sustentabilidade no planeta, evidenciando que é uma responsabilidade coletiva, e ações para melhorar o ambiente global são necessárias, o que inclui a adoção de práticas de produção e consumo sustentáveis. O objetivo do artigo é realizar uma análise crítica sobre a Produção mais Limpa (PmaisL) e a Avaliação do Ciclo de Vida (ACV) como 
metodologias imprescindíveis para o desenvolvimento sustentável. Constatou-se que as duas metodologias são eficazes para o ecodesenvolvimento, no qual a PmaisL está mais focada na redução de resíduos gerados internamente, enquanto a ACV engloba todo o ciclo de produção, desde a extração da matéria prima até a disposição do produto e seu retorno ao meio ambiente, conscientizando o meio empresarial para a aplicação das duas metodologias, no propósito de preservar o meio ambiente e, ainda, diminuir seus custos operacionais.

\section{RESULTADOS E DISCUSSÕES}

Para analisar a compreensão dos alunos acerca da sustentabilidade, utilizou-se alguns autores que exploram sobre a temática da sustentabilidade. Entre eles, Amador (2007), que afirma ser a sustentabilidade um conceito sistêmico, relacionado com a continuidade dos aspectos econômicos, sociais, culturais e ambientais da sociedade. Além disso, devem ser levados em conta quatro requisitos básicos, quando pensamos em sustentabilidade: ecologicamente correto, economicamente viável, socialmente justo e culturalmente aceito.

Grande parte dos discentes, ao responderem sobre o entendimento de sustentabilidade, consideraram a dimensão ambiental, conforme observado nos nas respostas a seguir:

"O nosso padrão de consumo já se tornou insustentável há muito tempo, causando prejuízos irreparáveis ao meio ambiente". (A2)

"Hoje o mundo tão capitalista e as pessoas pensando apenas no dinheiro e no consumo, não veem que afetam indiretamente a terra, pois quanto mais consumo, mais está sendo a demanda, e maior será a fabricação, assim maior consumo de matéria-prima e energia, sem falar na poluição, do ar e água". (A4) 
"[...] o consumo desenfreado deve começar a ser consciente, já que existe várias alternativas como brechós, customização entre outros". (A20)

O consumo acaba pertencendo a uma rotina na vida cotidiana, muitas vezes em uma intensidade tão grande, que se faz presente sem, ao menos, ser percebido como nocivo. Köhler e Dornbusch (2008) alertam sobre as atitudes simples na vida como reduzir o consumo, reciclar o lixo, não desperdiçar água e energia e outras ações que, na visão desses autores, são de grande importância para a minimização dos problemas ambientais e para a promoção da sustentabilidade.

Vale ressaltar que esse comportamento, no que concerne ao padrão de consumo atual, foi construído em grande parte a partir da Revolução Industrial, no século $X X$, e tem se estendido pela publicidade e pelo sistema da moda, pelo interesse das indústrias e lojas em vender cada vez mais. Com referência aos produtos do vestuário de moda, o pesquisador italiano Carlo Vezzoli, do Instituto Politécnico de Milão, propõe alguns cenários para um consumo mais consciente, salientando que, se as tendências de moda se posicionarem a favor do uso de materiais orgânicos, reciclados, reaproveitados, menos poluentes, mostrando-se contrárias ao uso de peles de animais, entre outros, haverá consequente contribuição para a produção e o consumo de produtos sustentáveis. Uma moda mais sustentável é um dos grandes desafios deste início de século XXI, visto que, no momento, os valores dos consumidores estão em alta e buscam novos caminhos para o consumo de produtos de moda. Esse pode ser um novo caminho para a sustentabilidade, visto que os consumidores expressam desejos de consumo por aquilo que está em evidência (KÖHLER; DORNBUSCH, 2008). 
Ressaltando a evolução dos acadêmicos frente a suas concepções iniciais em relação à sustentabilidade, podemos perceber que alguns deles apresentaram, em seus textos, preocupação com o consumo consciente. Vale destacar que o acadêmico $A 7$, em resposta ao questionário diagnóstico, apresentou total desconhecimento do tema. Em contrapartida, o seu texto apresentou um progresso significativo em relação ao seu entendimento, conforme exemplificado abaixo:

"Temos que começar a adquirir novos hábitos e começar a consumir produtos sustentáveis para preservarmos nosso planeta". (A7)

Na sequência, as respostas de outros acadêmicos dão enfoque no consumo de produtos sustentáveis:

"Muitas marcas já estão colocando em suas coleções algumas peças desenvolvidas de maneira sustentável. [...] Faz-se necessário mostrar ao consumidor que um produto sustentável também é legal e bonito, um dos grandes desafios do Designer de Moda é esse". (A9)

"Outra medida que a moda esta adotando é uma nova postura de consumo, visto que está surgindo um novo tipo de consumidor, que é adepto ao consumo consciente mais responsável". (A18).

De acordo com Jacobi (2005), o desenvolvimento sustentável depende do equilíbrio dinâmico entre os três pilares: econômico, ambiental e social. O desenvolvimento econômico refere-se à geração de riqueza; a proteção ambiental diz respeito aos impactos no sistema natural e social; e a inclusão social aborda os problemas relacionados com a má distribuição de rendimento, saúde e oportunidades. Torna-se cada vez mais necessário consolidar esses paradigmas, e isso propõe novos objetos de referência, principalmente, a transformação de atitudes. Nesse contexto, torna-se um desafio conciliar a moda com o 
desenvolvimento ambientalmente sustentável. Pelo individualismo, o sujeito está pouco disposto a considerar o interesse geral e a renunciar os privilégios adquiridos. Vale lembrar que as ações em conjunto são importantes para a questão da sustentabilidade, conforme argumenta Lipovetsky (2010), ao afirmar que, indubitavelmente, as ações para um mundo sustentável dependem da conscientização individual e coletiva, estamos perante um grande desafio, tanto para a moda, quanto para toda a sociedade humana.

A partir dos resultados obtidos por meio da produção textual dos acadêmicos, pode-se inferir que a intervenção pedagógica desenvolvida propiciou mudanças significativas no conhecimento dos participantes da pesquisa com relação à temática sustentabilidade.

\section{CONSIDERAÇÕES FINAIS}

Os problemas ambientais, enfrentados hoje, são decorrentes dos modos de vida que a humanidade tem adotado ao longo do tempo, priorizando a própria sobrevivência. Para tanto, faz uso dos recursos naturais de maneira exacerbada, não respeitando os limites de tempo da natureza.

Para abordar a questão da sustentabilidade, entre outros autores, destaca-se Amador (2007), que discute a sustentabilidade como um conceito sistêmico, relacionado com a continuidade dos aspectos econômicos, sociais, culturais e ambientais da sociedade humana, considerando também os quatro requisitos básicos: ecologicamente correto, economicamente viável, socialmente justo e culturalmente aceito. Lipovetsky (2010) complementa ao tecer argumentos sobre a importância das ações em conjunto para a eficácia da sustentabilidade. Desse modo, as ações para um mundo sustentável dependem, fortemente, 
da coletividade, que se caracteriza como um grande desafio tanto para a moda, quanto para toda a sociedade humana.

Diante dessas preocupações, apresenta-se os resultados obtidos por meio deste trabalho. Ressaltando que, no início da pesquisa, os acadêmicos pesquisados ao explicitarem a compreensão que tinham sobre sustentabilidade, destacaram apenas a dimensão ambiental. Após o desenvolvimento da intervenção pedagógica, os acadêmicos ampliaram a visão de sustentabilidade, percebendo, também, os aspectos econômico e social, uma vez que, nos seus textos produzidos, destacaram questões importantes, tais como consumo consciente, modelo econômico atual incompatível com a prática da sustentabilidade, importância da coletividade e de sociedades sustentáveis. Identifica-se, também, a mudança de visão dos acadêmicos com relação aos recursos que contribuem para a sustentabilidade no campo da moda.

Após a participação nesta pesquisa, os acadêmicos, mesmo trazendo a questão da reciclagem, apontaram aspectos importantes entre os quais, a diminuição de consumo para a preservação de recursos, o desenvolvimento de produtos com pouco consumo de energia, o cuidado com o destino dos resíduos produzidos e, ainda, repensaram as atitudes em relação à sustentabilidade.

Com base nos resultados, pode-se constatar que é possível, durante a formação inicial do profissional da moda, desenvolver o compromisso com a sustentabilidade ambiental. Nessa perspectiva, Birkeland (2002) afirma que os designers são potenciais agentes de mudança, uma vez que as suas decisões podem impedir, alertar, orientar ou influenciar as decisões futuras. Os designers reconhecem que a inovação e a criatividade são ferramentas determinantes para conseguir descobertas e mudanças significativas nos produtos, sendo, por isso, candidatos 
óbvios para lidar com a sustentabilidade, podendo desempenhar um valioso papel no desenvolvimento de uma nova cultura sustentável.

\section{REFERÊNCIAS}

AGUIAR, C. N.; MARTINS, E. P.; MATOS, R. N. A importância do consumo consciente no mercado de Moda. Disponível em: http://www.coloquiomoda.com.br/anais/anais/6-Coloquiode-

Moda_2010/71632_A_importancia_do_consumo_consciente _no_mercado_de_Moda. Acesso em: 8 maio 2013.

AMADOR, M. B. M. Sustentabilidade: constatação de uma prática, ainda, abissal em ambiente rural. Palestra proferida no III Fórum Ambiental da Alta Paulista, Tupã-SP, 4 set. 2007.

BARTHES, R. Inéditos. São Paulo: Martins Fontes, 2005.

BARTHES, R. Sistema da moda. Lisboa: Edições 70, 1967.

BENVENUTI, C. Desenvolvimento humano Sustentável. In: Encontro de sustentabilidade em projeto do vale do itajaí, 2., 2008, Balneário Camboriú-SC. Anais [...] Balneário Camboriú-SC: Universidade do Vale do Itajaí, 2008, p. 220-235. Disponível em: http://www.ubqrj.com.br/cbqp\%5CEcodesign_ sustent.pdf. Acesso em: 5 jul. 2012.

BERLIM, L. Moda e sustentabilidade: uma reflexão necessária. São Paulo: Estação das Letras e Cores, 2012.

BIRKELAND, J. Design for Sustainability: a soucebook of integrated eco-logical solutions. London: Earthscan Publications, 2002.

BOGDAN. R.; BIKLEN, S. Investigação Qualitativa em Educação: uma introdução à teoria e aos métodos. Portugal: Porto. 1994.

BRASIL. Resolução no. 2, de 15 de junho de 2012. Estabelece as Diretrizes Curriculares Nacionais para a Educação Ambiental. Diário Oficial da União, Brasília, DF, 18 jun. 2012. Seção 1, p. 70.

CALANCA, D. História social da Moda. São Paulo: SENAC, 2008 
DIAS, G. F. Educação Ambiental: princípios e práticas. 9. ed. São Paulo: Gaia, 2004.

GOULART, C. As práticas orais na escola: o seminário como objeto de ensino. 2005. 210 f. Dissertação (Mestrado em Lingüística Aplicada) - Instituto de Estudos da Linguagem, Universidade Estadual de Campinas, Campinas, 2005.

HINZ, R. T. P.; VALENTINA L. V. D.; FRANCO, A. C. Sustentabilidade ambiental das organizações através da produção mais limpa ou pela avaliação do ciclo de vida.

Revista Estudos tecnológicos - Vol. 2, $n^{\circ}$. 2:91-98 (jul/dez. 2006) Disponível em: http://revistas.unisinos.br/index.php/estudos_tecnologicos/a rticle/view/6078. Acesso em: 13 maio 2013.

JACOBI, P. Educação ambiental, cidadania e sustentabilidade. Cadernos de Pesquisa, São Paulo: Autores Associados, no. 118, p. 189-205, 2005.

JOFFILY, R. O Brasil tem Estilo? Rio de Janeiro: Senai, 1999.

KÖHLER, C. História do vestuário. São Paulo: Martins Fontes, 2005.

LEFF, E. Saber Ambiental: sustentabilidade, racionalidade, complexidade, poder. Petrópolis: Vozes, 2001.

LIPOVETSKY, G. O Império do Efêmero: a moda e seu destino nas sociedades modernas. São Paulo: Companhia das Letras, 2010.

MANZINI, E.; VEZZOLI, C. O desenvolvimento de produtos sustentáveis: os requisitos ambientais dos produtos industriais. Tradução de Astrid de Carvalho. 1. ed. 2. reimpr. São Paulo: Editora da Universidade de São Paulo, 2008.

MARTÍN, M. M. Formación para La ciudadanía y educación Superior. Revista iberoamericana de Educación, no. 42, p. 85-102, 2006. Disponível em: http://dialnet.unirioja.es/servlet/articulo?codigo $=2259860$.

Acesso em: 19 maio 2013.

MELLO, C. I.; CASTELLANELLI, C. A.; RUPPENTHAL, J. E.; BRONDANI, J. Preocupação com a questão ambiental através do design para o ciclo de vida: projeto de uma cadeira residencial. In: Encontro de sustentabilidade em projeto do vale do itajaí, 1., 2007, Balneário Camboriú-SC. Balneário Camboriú-SC: Universidade do Vale do Itajaí, 2007, p. 50-65. 
PEREIRA, J. V. I. Sustentabilidade: diferentes perspectivas, um objectivo comum. Economia Global e Gestão, Lisboa, v. 14, no. 1, abr. 2009. Disponível em: http://www.scielo.mec.pt/pdf/egg/v14n1/v14n1a08.pdf. Acesso em: 16 jul. 2012.

PEZZOLO, D. B. Tecidos: história, tramas, tipos e usos. São Paulo: Editora Senac São Paulo, 2007.

REFOSCO1, E.; MAZZOTTI, K.; SOTORIVA, M.; BROEGA, A. $C$. $O$ novo consumidor de moda e a Sustentabilidade. In: VII Colóquio de Moda. 2011. Disponível em: http://hdl.handle.net/1822/14946. Acesso em: 13 maio 2013.

REIGOTA, M. Meio Ambiente e Representação Social. São Paulo: Cortez, 1995.

ROCHE, D. La culture des apparances: une historire du vêtement XVIIe-XVIII siècle. Paris: Fayard, 1989.

SCHULTE, N. K.; LOPES, L. Sustentabilidade ambiental: um desafio para a moda. Modapalavra e-periódico. Ano $1, \mathrm{n}^{\circ}$. 2, ago-dez 2008, p. 30-42. ISSN 1982-615x

SCHULTE, N. K. Moda: da estética à ética ambiental biocêntrica. In: Ensus: II Encontro de Sustentabilidade em Projeto do Vale do Itajaí. 2008. Disponível em: http://ensus2008. paginas.ufsc.br/files/2015/09/Moda-daest\%C3\%A9tica-a-\%C3\%A9tica.pdf. Acesso em: 20 maio 2013.

SIMMEL, G. Cultura Feminine y outros Ensayos. Ciudad Del México: Espasa Calpe, 1961.

SORCINELLI, P. Estudar a moda: corpos, vestuário, estratégias. São Paulo: Senac. 2008. 